\title{
Imbalanced chordal force distribution causes acute ischemic mitral regurgitation: Mechanistic insights from chordae tendineae force measurements in pigs
}

\author{
Sten Lyager Nielsen, MD, PhD \\ Søren B. Hansen, MD, PhD \\ Katrine 0. Nielsen, MD \\ Hans Nygaard, DMSc \\ Peter K. Paulsen, MD, DMSc \\ J. Michael Hasenkam, MD, DMSc
}

\footnotetext{
From the Department of Cardiothoracic and Vascular Surgery and Institute of Clinical Medicine, Skejby Sygehus, Aarhus University Hospital, Aarhus, Denmark.

Supported by grants from the Danish Heart Foundation (96-1-3-58-22370 and 96-2-220-22417), The Danish Medical Research Council, and the Research Initiative of Aarhus University Hospital.
}

Received for publication April 15, 2004; revisions received July 21, 2004; accepted for publication July 26, 2004.

Address for reprints: Sten Lyager Nielsen, MD, Department of Cardiothoracic and Vascular Surgery, Skejby Sygehus, Aarhus University Hospital, 8200 Aarhus N, Denmark (E-mail: lyager@ki.au.dk).

J Thorac Cardiovasc Surg 2005;129:525-31 $0022-5223 / \$ 30.00$

Copyright (C) 2005 by The American Association for Thoracic Surgery

doi:10.1016/j.jtcvs.2004.07.044
Background: Ischemic mitral regurgitation is caused by an imbalance of the entire mitral-ventricular complex. This interaction is mediated through the chordae tendineae force distribution, which may perturb several elements of the mitral valve apparatus. Our objective was to investigate the association between the mitral valvular 3-dimensional geometric perturbations and chordae tendineae force redistribution in a porcine model of acute ischemic mitral regurgitation.

Methods: In 9 pigs, acute ischemic mitral regurgitation was induced by repeated microembolization of the left circumflex coronary artery. Mitral leaflet coaptation geometry was determined by 2-dimensional echocardiography and reconstructed 3-dimensionally. Leading edge chordal forces were measured by dedicated miniature force transducers at control and during ischemic mitral regurgitation.

Results: During acute ischemic mitral regurgitation, there was a decreased tension of the primary chorda from the ischemic posterior left ventricular wall to the anterior leaflet $(0.295 \pm 0.063 \mathrm{~N}$ vs $0.336 \pm 0.071 \mathrm{~N}$ [control]; $P<.05)$. The tension of the chorda from the nonischemic anterior left ventricular wall to the anterior leaflet increased $(0.375 \pm 0.066 \mathrm{~N}$ vs $0.333 \pm 0.071 \mathrm{~N}$ [control]; $P<.05)$. In accordance, relative leaflet prolapse was observed at the ischemic commissural side, whereas there was an increase in the leaflet surface area at the nonischemic commissural side, indicating localized leaflet tethering.

Conclusions: Acute ischemic mitral regurgitation due to posterior left ventricular wall ischemia was associated with focal chordal and leaflet tethering at the nonischemic commissural portion of the mitral valve and a paradoxical decrease of the chordal forces and relative prolapse at the ischemic site of the anterior mitral valve leaflet.

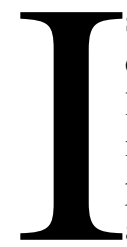

schemic mitral valve regurgitation (IMR) remains a common and morbid clinical problem that affects long-term prognosis and mortality after revascularization. ${ }^{1}$ The treatment of IMR remains as controversial as its underlying mechanisms. A better mechanistic understanding of functional IMR will help to provide a rational basis for optimal surgical management of IMR, also with the aim to improve left ventricular (LV) function.

There is a widespread clinical acceptance of the association between incomplete mitral leaflet coaptation and IMR. ${ }^{2}$ Prevailing explanations for the incomplete closure of the mitral leaflets have focused on the ischemic distortion of LV geometry displacing the attachments of the mitral leaflets to the papillary muscles (PMs) and 

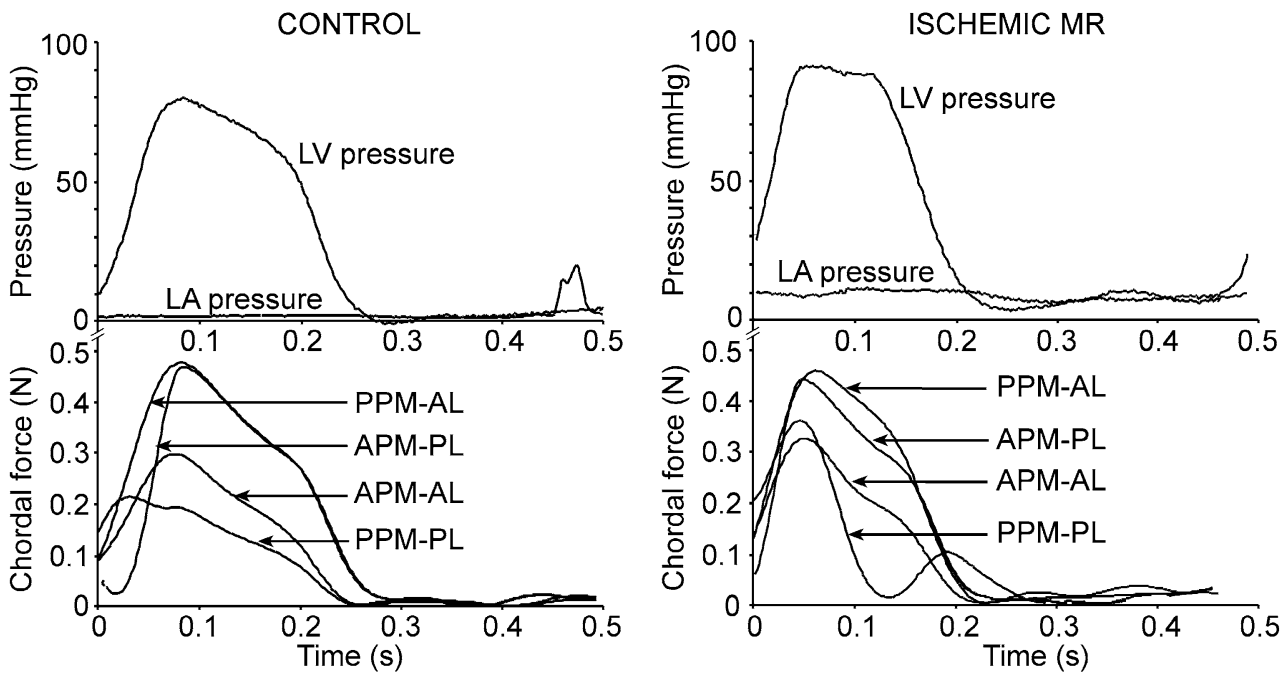

Figure 1. Time course of the chordae tendineae forces in relation to the LV and left atrial (LA) pressure at control (left) and during acute ischemic mitral regurgitation (right) from 1 animal. Data are aligned at end-diastole (time 0). APM-AL, APM-PL, PPM-AL, and PPM-PL, chordae from the anterolateral (APM) and posteromedial (PPM) papillary muscle to the anterior $(A L)$ and posterior $(P L)$ mitral leaflet; $M R$, mitral regurgitation.

mitral annulus and restricting their ability to close effectively. ${ }^{3}$ Suggestive clinical evidence of localized mitral leaflet prolapse in some patients with regional myocardial infarction $^{4-6}$ rather suggests functional IMR to be considered in a sequence of improper coordination of the entire mitral valve apparatus, which provides an imbalanced support of the mitral valve leaflets. ${ }^{4,6,7}$ In this context, a potential contributory role of PM contractile dysfunction impairing the normal support of effective coaptation has been debated. ${ }^{8}$ In the presence of IMR resulting from a net imbalance of apically directed tethering forces and diminished LV contraction, the normal PM contraction should in principle increase apical leaflet tethering and augment IMR. Conversely, contractile dysfunction or stretching of the ischemic PM can paradoxically diminish IMR by allowing the leaflets to seal better or can even result in mitral leaflet prolapse.

In previous in vitro experiments, ${ }^{3,9}$ we have advocated that interaction among the mitral valve components should comply with the concept of the chordal force equilibrium and have emphasized that redistribution of the chordal force balance leads to incomplete mitral leaflet coaptation. We have shown that PM misalignment causes a nonuniform remodeling of the mitral leaflet surface area and multiple mitral regurgitant jets, as observed clinically. ${ }^{2,5}$

On the basis of these experiments, this in vivo study in pigs aimed to test the hypothesis that acute IMR is directly associated with an altered force distribution of the chordae tendineae in ventricular systole. Therefore, the aim of the study was to measure the tension of 4 primary chordae tendineae and to investigate the association between the mitral valvular 3-dimensional geometric perturbations and the chordae tendineae force redistribution in a porcine model of acute IMR.

\section{Materials and Methods \\ Surgical Preparation}

The study material comprised 9 mixed Yorkshire and Danish Landrace pigs with a body weight of $80 \mathrm{~kg}$. After establishment of cardiopulmonary bypass and cardioplegic arrest, the mitral valve was exposed through a left atriotomy. The 2 major fixing primary ("marginal") chordae tendineae ${ }^{10}$ of the anterior and posterior leaflet were identified, and dedicated miniature $\mathrm{C}$-shaped force transducers were sutured to these chordae. Chordal continuity was maintained in series with the implanted transducers. ${ }^{11}$ Micromanometer pressure catheters (SPC-350MR; Millar Instruments, Inc, Houston, Tex) were placed in the LV and left atrial chamber, and the LV pressure catheter was exteriorized through a purse-string suture on the apex of the heart. The wires from the force transducers were tunneled intramyocardially around the anterolateral part of the mitral annulus and exteriorized together with the left atrial pressure catheter through the left atriotomy. Snares were placed around the superior and inferior venae cavae. The animals were weaned from cardiopulmonary bypass and studied intubated with the chest open by using continuous ketamine ( 8 $\left.\mathrm{mg} \cdot \mathrm{kg}^{-1} \cdot \mathrm{h}^{-1}\right)$ and diazepam $\left(1 \mathrm{mg} \cdot \mathrm{kg}^{-1} \cdot \mathrm{h}^{-1}\right)$ anesthesia.

After control echocardiographic imaging and hemodynamic recordings, a coronary guiding catheter was introduced through a 7F left carotid artery sheath and advanced into the left main coronary artery over a 0.0014 -inch high-torque floppy guidewire. A conventional $3.5-\mathrm{mm}$ balloon catheter was then advanced through the guiding catheter into the proximal left circumflex artery. A saline solution of microspheres $(2.5 \mathrm{~g} / \mathrm{L}$ Sephadex G-25 Fine [Amersham Biosciences Corp, Piscataway, NJ] with a particle size of $20-80 \mu \mathrm{m} ; 6-14 \mathrm{~mL}$ ) was repeatedly injected into the artery until acute myocardial ischemia in the posteromedial LV 
TABLE 1. Chordae tendineae force distribution

\begin{tabular}{|c|c|c|c|c|}
\hline \multirow{2}{*}{$\begin{array}{l}\text { Chordal } \\
\text { location }\end{array}$} & \multicolumn{2}{|c|}{ Control } & \multicolumn{2}{|c|}{ IMR } \\
\hline & $F(N)$ & $F_{P}(N)$ & $F(N)$ & $F_{P}(N)$ \\
\hline APM-AL & $0.348 \pm 0.085$ & $0.333 \pm 0.071$ & $0.300 \pm 0.053$ & $0.375 \pm 0.066^{*}$ \\
\hline APM-PL & $0.248 \pm 0.041$ & $0.278 \pm 0.064$ & $0.140 \pm 0.029$ & $0.205 \pm 0.044$ \\
\hline PPM-AL & $0.315 \pm 0.068$ & $0.336 \pm 0.071$ & $0.216 \pm 0.049$ & $0.295 \pm 0.063^{*}$ \\
\hline PPM-PL & $0.358 \pm 0.063$ & $0.392 \pm 0.085$ & $0.254 \pm 0.073$ & $0.387 \pm 0.089$ \\
\hline
\end{tabular}

$F$, Chordae tendineae tension; $F_{P}$, normalized chordae tendineae tension (to a left ventricular pressure of $100 \mathrm{~mm} \mathrm{Hg}$ ) of major primary chordae tendineae from the anterolateral (APM) and posteromedial (PPM) papillary muscle to the anterior ( $A L)$ and posterior (PL) mitral leaflet. Data are expressed as mean \pm 1 SEM.

$* P<.05$ for $\mathrm{F}_{\mathrm{P}}$ at IMR versus control with the Student $t$ test for paired observations.

wall was verified by electrocardiogram (ECG; ST segment elevation $>2 \mathrm{~mm}$ in the inferior leads) or echocardiography (akinetic/ dyskinetic wall motion), and IMR was observed by echocardiography. The microembolization technique was preferred instead of ligation or balloon catheter occlusion of the coronary artery, which in this pig model causes malignant ventricular arrhythmias. The embolization technique has previously been validated in our institution. In acute studies, it produces acute regional myocardial infarction. ${ }^{12}$ From chronic studies using this technique, ${ }^{13}$ autopsy has demonstrated transmural regional myocardial infarction after repeated coronary embolizations.

Hemodynamic data and echocardiographic recordings were obtained during steady-state conditions immediately before (control) and 30 minutes after coronary microembolization (IMR), for LV wall dyskinesia and IMR to develop. Animal handling was performed in accordance with the guidelines from the Danish Inspectorate of Animal Experimentation and was approved by this institution.

\section{Data Acquisition}

Hemodynamics. The microtip pressure catheters (SPC350MR) recorded LV and left atrial pressures. The chordal force transducers were coupled to a strain gauge amplifier (model 2021; Measurement Group Inc, Raleigh, NC). During data acquisition, chordal force, LV and left atrial pressure, and ECG voltage analog signals were simultaneously recorded on a data recorder (XR-510; TEAC, Tokyo, Japan) for subsequent offline analysis.

Echocardiography. Two-dimensional echocardiographic recordings from 15 rotated LV apical views were acquired by epicardial echocardiography by using an ultrasound scanner (System FiVe; GE Medical, formerly Vingmed, Horten, Norway) equipped with a $5-\mathrm{MHz}$ transesophageal probe. The probe was placed manually behind the pericardium of the left atrium in the open-chest animal to ensure optimal acoustic contact. The 15 rotated LV apical views were acquired with suspended respiration. Digital cineloop images, along with the ECG, were downloaded to a computer for offline analysis facilitated by commercially available software (EchoPAC version 5.4; Vingmed).

\section{Data Analysis}

Hemodynamics. All recorded analog signals were converted to digital data by an analog-to-digital converter with a sampling frequency of $400 \mathrm{~Hz}$ (AT-MIO-16-E2; National Instruments, Austin, Tex) controlled by dedicated software developed in LabVIEW

\section{TABLE 2. Mitral valve variables}

\begin{tabular}{lcc}
\hline Variable & Control & IMR \\
\hline $\mathrm{A}_{\mathrm{MA}}\left(\mathrm{cm}^{2}\right)$ & $9.4 \pm 0.4$ & $10.6 \pm 0.6$ \\
$\mathrm{~A}_{\mathrm{MA}-\mathrm{AC}}\left(\mathrm{cm}^{2}\right)$ & $4.9 \pm 0.3$ & $6.1 \pm 0.5^{*}$ \\
$\mathrm{~A}_{\mathrm{MA}-\mathrm{PC}}\left(\mathrm{cm}^{2}\right)$ & $4.5 \pm 0.3$ & $4.5 \pm 0.3$ \\
$\mathrm{~A}_{\mathrm{L}}\left(\mathrm{cm}^{2}\right)$ & $10.2 \pm 1.2$ & $11.6 \pm 2.0^{*}$ \\
$\mathrm{~A}_{\mathrm{AC}}\left(\mathrm{cm}^{2}\right)$ & $5.3 \pm 0.7$ & $6.6 \pm 1.3^{*}$ \\
$\mathrm{~A}_{\mathrm{AC}-\mathrm{AL}}\left(\mathrm{cm}^{2}\right)$ & $2.7 \pm 0.3$ & $3.7 \pm 0.9^{*}$ \\
$\mathrm{~A}_{\mathrm{AC}-\mathrm{PL}}\left(\mathrm{cm}^{2}\right)$ & $2.5 \pm 0.7$ & $2.9 \pm 0.9$ \\
$\mathrm{~A}_{\mathrm{PC}}\left(\mathrm{cm}^{2}\right)$ & $4.9 \pm 0.8$ & $5.0 \pm 0.9$ \\
$\mathrm{~A}_{\mathrm{PC}-\mathrm{AL}}\left(\mathrm{cm}^{2}\right)$ & $2.6 \pm 0.5$ & $2.9 \pm 0.7$ \\
$\mathrm{~A}_{\mathrm{PC}-\mathrm{PL}}\left(\mathrm{cm}^{2}\right)$ & $2.3 \pm 0.5$ & $2.1 \pm 0.8$ \\
$\mathrm{~h}_{\mathrm{AC}}(\mathrm{cm})$ & $0.42 \pm 0.19$ & $0.57 \pm 0.16^{*}$ \\
$\mathrm{~h}_{\mathrm{PC}}(\mathrm{cm})$ & $0.46 \pm 0.20$ & $0.26 \pm 0.22^{*}$ \\
\hline$A_{M}$ &
\end{tabular}

$A_{L}$,Total leaflet surface area and leaflet surface areas of the anterolateral $\left(A_{A C}\right)$ and posteromedial $\left(A_{P C}\right)$ half-portion of the anterior $\left(A_{A C-A L}\right.$ and $\left.A_{P C-A L}\right)$ and posterior $\left(A_{A C-P L}\right.$ and $\left.A_{P C-P L}\right)$ leaflet; anterolateral $\left(A_{M A-A C}\right)$ and posteromedial $\left(A_{M A-P C}\right)$ portion of the mitral annular area $\left(A_{M A}\right) ; h_{A C}$ and $h_{P C}$, heights of the coaptation points between the leaflets at the anterolateral and posteromedial commissure. Data are expressed as mean \pm SEM.

$* P<.05$ at IMR versus control with the Student $t$ test for paired observations.

(National Instruments). Zero adjustment of the chordae force signals was accomplished during sustained vena cava occlusion, because the chordae were assumed to be slackened (as confirmed by echocardiogram) in the unloaded heart. The maximum chordae tendineae tension and corresponding LV pressure in mid systole were depicted graphically in 3 representative heart cycles during vena cava occlusion. Linear regression analysis was used for estimating the equation representing the relationship between chordal tension and LV pressure. ${ }^{14}$ Chordae tendineae tension was then normalized to a $\mathrm{LV}$ pressure of $100 \mathrm{~mm} \mathrm{Hg}\left(\mathrm{F}_{\mathrm{P}}\right)$ before and after intervention.

Echocardiography. Mitral valve geometry was analyzed in mid systole, defined as the time of the closest approach between the mitral leaflet coaptation point and the mitral annulus plane and corresponding to peak LV pressure and peak chordal tension.

The least-square plane of the mitral annular hinge points was established as a reference frame; projecting the mitral annulus onto this plane gave an estimate of mitral annular area $\left(A_{M A}\right)$. The 

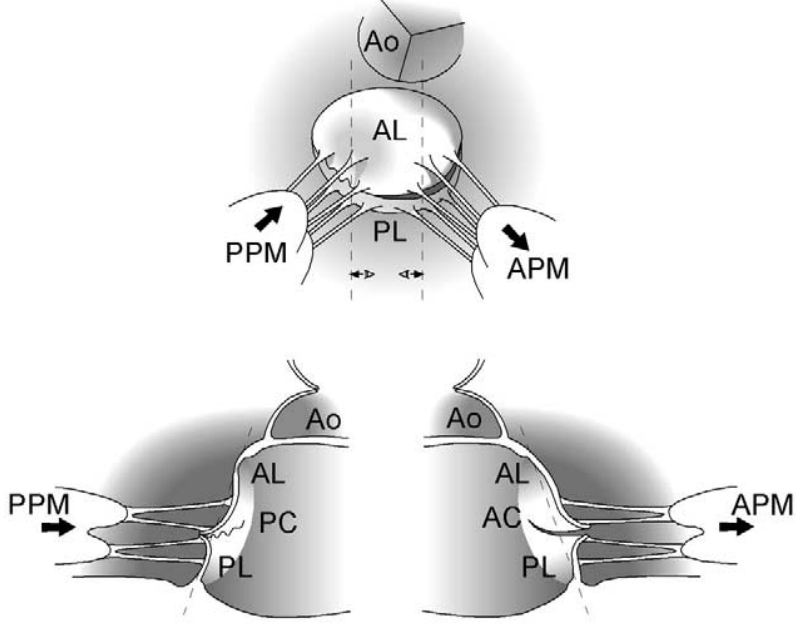

Figure 2. Mitral leaflet coaptation geometry during acute ischemic mitral regurgitation from the apical view (top) and the sagittal views toward the posteromedial commissure (PC) (bottom left) and the anterolateral commissure (AC) (bottom right). Redistribution of the chordae tendineae forces during ischemia resulted in relative leaflet prolapse at the $\mathrm{PC}$ and leaflet tethering at the AC. $A L$ and $P L$, Anterior and posterior mitral valve leaflet; $A$, aorta; $P P M$, posteromedial papillary muscle; $A P M$, anterolateral papillary muscle.

3-dimensional leaflet surface area $\left(\mathrm{A}_{\mathrm{L}}\right)$ separating the left atrial and $\mathrm{LV}$ cavities (excluding the coaptation area between the leaflets) was reconstructed from intersecting leaflet traces according to an algorithm previously described. ${ }^{3} \mathrm{~A}_{\mathrm{L}}$ was the minimum surface area needed to occlude the orifice, as dictated by the shape of the mitral leaflets. Therefore, a small difference between $A_{M A}$ and $A_{L}$ indicates a flattened leaflet contour; a big difference is indicative of bulging leaflets caused either by tenting or prolapse. On the basis of this calculation, the leaflet surface area of the anterolateral $\left(\mathrm{A}_{\mathrm{AC}}\right)$ and posteromedial $\left(\mathrm{A}_{\mathrm{PC}}\right)$ commissural half-portions of $\mathrm{A}_{\mathrm{L}}$ and the parts constituted by the anterior and posterior mitral leaflet $\left(\mathrm{A}_{\mathrm{AC}-\mathrm{AL}}, \mathrm{A}_{\mathrm{AC}-\mathrm{PL}}, \mathrm{A}_{\mathrm{PC}-\mathrm{AL}}\right.$, and $\left.\mathrm{A}_{\mathrm{PC}-\mathrm{PL}}\right)$ could easily be calculated. The relative change of these surface areas in comparison to the normal condition thus reflected the changes of leaflet tenting and the severity of incomplete mitral leaflet closure.

The heights of the coaptation points between leaflets, $\mathrm{h}_{\mathrm{AC}}$ between the posterior leaflet's P1 and the anterior leaflet's A1 and $\mathrm{h}_{\mathrm{PC}}$ between the posterior leaflet's P2 and the anterior leaflet's A2, of the apical view crossing the 2 commissures (approximately $60^{\circ}$ ) were also reported to compare leaflet tenting of the anterolateral and posteromedial commissural half-portion from a single image plane.

Estimates of LV end-systolic (ESV) and end-diastolic (EDV) volumes and ejection fraction (EF) were determined from endocardial LV tracings from 3 apical scanning planes $\left(60^{\circ}\right.$ interval) by using modified Simpson rule formulas for calculating volumes. ${ }^{15}$

IMR was assessed and graded on a +1 to +4 scale (mild, moderate, moderate-severe, and severe) on the basis of epicardial Doppler echocardiography. The location and direction of the regurgitant jet were assessed by color Doppler flow mapping.

\section{Statistical Analysis}

All data are reported as mean \pm SEM. Peak chordal force normalized to pressure during systole in each of the 4 primary chordae was compared at control and after infarction by the 2-tailed $t$ test for paired comparisons. The leaflet surface areas and leaflet heights at the commissures, the LV volumes, and the grade of IMR were compared at control and after infarction by the 2-tailed $t$ test for paired comparisons.

\section{Results \\ Hemodynamics}

Posterior LV wall infarction reduced the average LV pressure $(76 \pm 4 \mathrm{~mm} \mathrm{Hg}[\mathrm{IMR}]$ vs $95 \pm 4 \mathrm{~mm} \mathrm{Hg} ; P<.05)$ and the peak positive rate change of $\mathrm{LV}$ pressure $(1869 \pm 269$ $\mathrm{mm} \mathrm{Hg} / \mathrm{s}[\mathrm{IMR}]$ vs $2242 \pm 266 \mathrm{~mm} \mathrm{Hg} / \mathrm{s} ; P<.05)$. Heart rate did not significantly change $(108 \pm 5 \mathrm{bpm}$ [IMR] vs $114 \pm 4 \mathrm{bpm})$.

\section{Dimension}

Posterior LV wall infarction was associated with increased LV ESV $(32 \pm 5 \mathrm{~mL}$ [IMR] vs $22 \pm 2 \mathrm{~mL} ; P<.05) . \mathrm{LV}$ EDVs did not significantly change $(53 \pm 9 \mathrm{~mL}$ [IMR] vs 50 $\pm 2 \mathrm{~mL})$. EF decreased from $54 \%$ to $38 \%(P<.05)$.

\section{Mitral Regurgitation}

Before embolization, 2 animals had trace IMR; no IMR was observed in the remaining animals. After infarction, 1 animal had grade $1+, 5$ animals had grade $2+$, and 3 animals grade $3+$. Overall, the IMR grade increased from $0.1 \pm 0.1$ to $2.2 \pm 0.2(P<.001)$. On color Doppler velocity mapping, the IMR was holosystolic and was located centrally or extending toward the anterior commissure. The IMR jet was directed either centrally or toward the posterior left atrial wall.

\section{Chordal Force Distribution}

Figure 1 shows from 1 experiment traces of chordae tendineae tension of the primary chordae in relation to $\mathrm{LV}$ pressure at control and IMR. Table 1 shows the peak systolic chordae tendineae tension and the tension normalized to a $\mathrm{LV}$ pressure of $100 \mathrm{~mm} \mathrm{Hg}\left(\mathrm{F}_{\mathrm{P}}\right)$ of the individual chordae before and after infarction. $\mathrm{F}_{\mathrm{P}}$ increased in 7 of 8 complete data sets from the primary chordae connecting the anterolateral PM and anterior leaflet. $\mathrm{F}_{\mathrm{P}}$ decreased in 8 of 9 complete data sets from the primary chordae connecting the posteromedial PM and anterior leaflet; both were statistically significant. The $\mathrm{F}_{\mathrm{P}}$ of the remaining 2 primary chordae did not change after infarction.

\section{Mitral Valve Geometry}

Table 2 summarizes the mitral annular areas $\left(A_{M A}, A_{M A-A C}\right.$, and $\left.A_{M A-P C}\right)$, the total leaflet surface area $\left(A_{L}\right)$, the commissural half-portions of the leaflet surface area $\left(\mathrm{A}_{\mathrm{AC}}\right.$ and 
$\left.\mathrm{A}_{\mathrm{PC}}\right)$, and the part formed by each of the leaflets $\left(\mathrm{A}_{\mathrm{AC}-\mathrm{AL}}\right.$ $\mathrm{A}_{\mathrm{AC}-\mathrm{PL}}, \mathrm{A}_{\mathrm{PC}-\mathrm{AL}}$, and $\mathrm{A}_{\mathrm{PC}-\mathrm{PL}}$ ) before and after embolization. Posterior wall infarction significantly increased $\mathrm{h}_{\mathrm{AC}}$ and the anterolateral commissural half-portions of the leaflet surface area, $\mathrm{A}_{\mathrm{AC}}$, mediated through expansion of both the anterior and posterior leaflets. In contrast, the posteromedial halfportion of the leaflet surface area, $A_{P C}$, was not affected by infarction. Therefore, the increase in $\mathrm{h}_{\mathrm{AC}}$ and $\mathrm{A}_{\mathrm{AC}}$ was apparently caused by increased leaflet tenting at the anterolateral commissural side, whereas the decrease in $h_{\mathrm{PC}}$ indicated a relative prolapse of the leaflets at the posteromedial commissural side.

\section{Discussion}

In this pig study, acute posterior LV wall infarction was accompanied by multiple alterations of the mitral valve apparatus, any one of which may lead to IMR. The chordal force measurements provided direct evidence that this functional IMR should be considered in a sequence of improper coordination of the entire mitral valve apparatus, which provides an unbalanced support to the mitral valve leaflets. ${ }^{4,6,7}$ Acute posterior LV wall infarction was associated with increased chordal tethering from the noninfarcted anterolateral PM to the anterior leaflet and, in contrast, decreased tethering from the infarcted posteromedial PM to the anterior leaflet. In accordance with these observations, the heights of the leaflet tip, the $\mathrm{A}_{\mathrm{MA}}$, and the leaflet surface area at the anterolateral commissural side increased, indicating a stretching and tenting of the leaflets at this side (probably because of unfolding of leaflet reserve). Surprisingly, the tension of the chordae from the anterolateral PM to the posterior leaflet tended to decrease during ischemia, although this was not statistically significant. One plausible explanation is that mitral leaflet malcoaptation (due to restrictive posterior leaflet motion and infolding of the anterior leaflet) reduces the posterior leaflet surface area exposed to the LV pressure. This will tend to reduce the chordal forces of the posterior leaflet and contribute to further mitral leaflet malcoaptation.

At the posteromedial commissural side the leaflet surface area was unchanged even when $\mathrm{A}_{\mathrm{MA}-\mathrm{PC}}$ increased slightly. Because the leaflet height at the infarcted side $\left(\mathrm{h}_{\mathrm{PC}}\right)$ decreased, we believe that the slackening of the chordae tendineae caused a localized prolapse of the leaflets on this side.

This process can be interpreted as follows. The remodeling (sphericalization) of the LV cavity by posterior wall infarction distorted the positioning of both PMs (Figure 2). Even though we did not directly study the PM dynamics, we assume that the systolic shortening of the intact anterolateral PM increased the chordal tethering and pulled the leaflets apart, resulting in localized IMR in this region. The lack of systolic shortening of the infarcted posteromedial PM will, despite the geometric changes of the LV cavity, pseudonormalize the suspension of the mitral leaflets or may even be responsible for relative leaflet prolapse, as we observed in this study. However, it should be noted that echocardiography did not demonstrate malcoaptation between the leaflet edges at the posteromedial commissure (Figure 2), and we did not observe significant regurgitation in this area.

One should also be aware that changes of the mitral leaflet shape and unfolding of the leaflet reserve because of increased chordal tethering also increase the pressure forces acting to close the leaflets, and this will tend to counteract the tethering forces of the chordae. The resultant leaflet coaptation geometry hereby becomes a result of the balance of the tethering and coapting forces of the chordae tendineae.

In a pulsatile in vitro model, which provided control of the mitral annulus shape and PM positioning, ${ }^{9}$ we have shown that functional IMR based on the tented leaflet configuration, as observed clinically, could be reproduced by PM malalignment. In that study, redirection of the chordal tethering force by posterolateral displacement of one PM caused a remodeling of the mitral leaflet surface area and resulted in regional anterior leaflet prolapse at the contralateral commissure and further leaflet malcoaptation. It is plausible that this mechanism contributed to the relative prolapse of the leaflets, as we observed in this study.

Our observations are supported by other experimental studies. In an acute ovine model, Gorman and associates ${ }^{7,16}$ produced moderate IMR by posterior LV wall infarction and showed by use of sonomicrometry that the most important changes were asymmetric annular dilatation, prolapse of leaflet tissue tethered by the posterior infarcted PM, and restriction of leaflet tissue attached to the anterolateral PM.

In an acute IMR model in dogs, Komeda and associates ${ }^{17}$ demonstrated that only the posterior mitral leaflet edge on the anterolateral commissural side dislocated toward the LV apex with IMR compared with no IMR. There was no change on the posteromedial commissural side. In their study, both PM tips were displaced radially, but not in an apical direction. In accordance with our findings, however, it has been reported that systolic dysfunction of the ischemic PM may ameliorate the effect of LV wall motion abnormalities. $^{8,18}$

Dagum and colleagues ${ }^{19}$ demonstrated repositioning of the PM tips relative to the mitral annulus during acute posterior LV wall ischemia in sheep: the distance between the anterolateral PM tip and the left fibrous trigone and posterior annulus increased during ischemia. The distance between the posteromedial PM tip and the posterior annulus decreased, suggesting that the posteromedial PM displaced posteriorly during ischemia. Because the distance between the PM tip and the leaflet edge distances must remain constant because of the chordae, they hypothesized that 
these perturbations unfavorably tethered the leaflet edges apically and predisposed to IMR.

Our study corroborated this issue further by demonstrating that the perturbed mitral leaflet coaptation geometry during acute IMR was directly related to an altered chordal force distribution.

It is important to emphasize that pathologic mechanistic factors of acute IMR may have limited clinical significance for the chronic presentation of IMR. Whereas multiple but subtle geometric changes lead to acute IMR, chronic IMR involves more extensive changes that cause moderate annular dilatation and complex leaflet tethering along the leaflet coaptation line. In a chronic infarct model in sheep, the development of chronic IMR was attributed to larger septolateral annular dilatation and posterolateral displacement of the posteromedial PM. ${ }^{20}$ In another ovine model, a combination of asymmetric annular dilatation and leaflet tethering by both PMs seemed to produce $\mathrm{IMR}^{21}$ : the posteromedial PM tip to the posteromedial commissure relationship did not change, but both PMs were displaced away from the anterolateral commissure. Therefore, the postinfarction ventricular remodeling process in this model tethered the anterolateral portion of both leaflets in a manner consistent with the proposed mechanisms of acute IMR in this study and those suggested by others. ${ }^{16,17}$ These findings are also supported by clinical observations of asymmetric leaflet deformation in patients with chronic IMR. ${ }^{5}$

Guided by chordal force measurements, this study has revealed potential mechanistic factors that may be involved in the pathogenesis of acute IMR. Although one must always be extremely cautious in extrapolating the results of open-chest animal experiments to the closed-chest human situation, our data suggest that an imbalanced chordal force distribution is a key factor that mediates the relative contribution and interaction of geometric and hemodynamic variables for acute IMR. Even if the pathogenesis of chronic IMR is different, it is reasonable to assume that the overall concept of an altered chordal force distribution is also valid in the chronic presentation of IMR.

Even though any clinical implications of this study must be stated circumspectly, the study lends further support to therapeutic strategies such as chordal reconstruction ${ }^{17,22}$ and PM repositioning ${ }^{23}$ that aim to restore the tethering imbalance that restricts mitral leaflet closure and causes IMR.

The results must be interpreted in light of several limitations inherent in this experiment. The data were obtained in an acute, open-chest setting immediately after a long and complicated cardiac surgical procedure-far from normal clinical circumstances. With attention to the time of cardioplegic arrest and to avoid interference between the transducers, we decided to implant 4 force transducers in this preparation. We obviously cannot make more subtle state- ments on the functional significance of individual chordae, for example, as regards a possible force redistribution between the primary and secondary chordae during ischemia. However, because tethering of, particularly, the strut chordae of the anterior leaflet recently has been proposed to be important for incomplete mitral leaflet coaptation, ${ }^{22}$ it would have been desirable if we could have provided such force data.

As discussed previously, the experiments were performed in normal pig hearts without the pathophysiologic deformation that may accompany chronic mitral regurgitation in patients. Also, the infarction was acute and was based on coronary microembolization, although the hemodynamic and LV remodeling effects-acute as well as chronic-have shown to mimic the clinical observations. The extent of myocardial damage by coronary microembolization was largely unpredictable and may furthermore have been confounded by myocardial stunning after cardiopulmonary bypass.

Another limitation of the study is the arbitrary external coordinate system defined by the transducer position and the translation and 3-dimensional reconstruction of the mitral valve and annular geometry. Flattening and regional distortion of the normal hyperbolic paraboloid shape (saddleshape) of the mitral annulus during ischemia ${ }^{24}$ may also have confounded the construction of the mitral leaflet coaptation geometry in relation to the mitral annulus; however, the consistency between the geometric data and the chordal force measurements supports the overall concepts of this study. Anatomic differences between human and pig mitral valve apparatus must also be considered, ${ }^{25}$ so the observed results may not be directly applicable to the human mitral valve.

We thank the Audio-Visual Group at Aarhus University Hospital for the illustrations.

\section{References}

1. Hickey MS, Smith LR, Muhlbaier LH, Harrell FE, Reves JG, Hinohara $\mathrm{T}$, et al. Current prognosis of ischemic mitral regurgitation: implications for future management. Circulation. 1988;78:I51-9.

2. Godley RW, Wann LS, Rogers EW, Feigenbaum H, Weyman AE. Incomplete mitral leaflet closure in patients with papillary muscle dysfunction. Circulation. 1981;63:565-71.

3. Nielsen SL, Nygaard H, Fontaine AA, Hasenkam JM, He S, Andersen NT, et al. Chordal force distribution determines systolic mitral leaflet configuration and severity of functional mitral regurgitation. J Am Coll Cardiol. 1999;33:843-53.

4. Stewart WJ, Currie PJ, Salcedo EE, Klein AL, Marwick T, Agler DA, et al. Evaluation of mitral leaflet motion by echocardiography and jet direction by Doppler color flow mapping to determine the mechanisms of mitral regurgitation. J Am Coll Cardiol. 1992;20:1353-61.

5. Kwan J, Shiota T, Agler DA, Popovic ZB, Qin JX, Gillinov MA, et al. Geometric differences of the mitral apparatus between ischemic and dilated cardiomyopathy with significant mitral regurgitation: real-time three-dimensional echocardiography study. Circulation. 2003;107: 1135-40.

6. Izumi S, Miyatake K, Beppu S, Park YD, Nagata S, Kinoshita N, et al. Mechanism of mitral regurgitation in patients with myocardial infarc- 
tion: a study using real-time two-dimensional Doppler flow imaging and echocardiography. Circulation. 1987;76:777-85.

7. Gorman JH III, Jackson BM, Gorman RC, Kelley ST, Gikakis N, Edmunds LH Jr. Papillary muscle discoordination rather than increased annular area facilitates mitral regurgitation after acute posterior myocardial infarction. Circulation. 1997;96:II124-7.

8. Messas E, Guerrero JL, Handschumacher MD, Chow CM, Sullivan S, Schwammenthal E, et al. Paradoxic decrease in ischemic mitral regurgitation with papillary muscle dysfunction: insights from three-dimensional and contrast echocardiography with strain rate measurement. Circulation. 2001;104:1952-7.

9. Nielsen SL, Nygaard H, Fontaine AA, Fontaine AA, Hasenkam JM, $\mathrm{He} \mathrm{S}$, et al. Papillary muscle misalignment causes multiple mitral regurgitant jets: an ambiguous mechanism for functional mitral regurgitation. J Heart Valve Dis. 1999;8:551-64.

10. Yacoub M. Anatomy of the mitral valve chordae and cusps. In: Kalmanson D, editor. The mitral valve. A pluridisciplinary approach. London: Edward Arnold; 1976. p. 15-20.

11. Nielsen SL, Soerensen DD, Libergren P, Yoganathan AP, Nygaard H. Miniature c-shaped transducers for chordae tendineae force measurements. Ann Biomed Eng. 2004;32:1050-7.

12. Terp K, Kim WY, Ulrich M, Frokiaer J, Baandrup U, Rehling M, et al. The hemodynamic impact of diffuse myocardial ischemic lesions: an animal experimental model based on intracoronary microembolization. Heart Vessels. 1998;13:132-41.

13. Terp K, Koudahl V, Veien M, Kim WY, Andersen HR, Baandrup U, et al. Functional remodelling and left ventricular dysfunction after repeated ischaemic episodes. A chronic experimental porcine model. Scand Cardiovasc J. 1999;33:265-73.

14. Lomholt M, Nielsen SL, Hansen SB, Andersen NT, Hasenkam JM. Differential tension between secondary and primary mitral chordae in an acute in-vivo porcine model. J Heart Valve Dis. 2002;11:337-45.

15. Kim WY, Terp KA, Nyengaard JR, Silkjaer T, Jensen FT. Unbiased and efficient estimation of left ventricular volumes by three-dimen- sional echocardiography with coaxial sections: validation with magnetic resonance imaging. Heart Vessels. 2000;15:35-43.

16. Gorman JH, Gorman RC, Jackson BM, Hiramatsu Y, Gikakis N, Kelley ST, et al. Distortions of the mitral valve in acute ischemic mitral regurgitation. Ann Thorac Surg. 1997;64:1026-31.

17. Komeda M, Glasson JR, Bolger AF, Daughters GT, MacIsaac A, Oesterle SN, et al. Geometric determinants of ischemic mitral regurgitation. Circulation. 1997;96(suppl):II128-33.

18. Komeda M, Glasson JR, Bolger AF, McIsaac A, Oesterle SN, Niczyporuk MA, et al. Mirror image "compensatory mechanism" of papillary muscles with posterior or anterior LV wall ischemia [abstract]. Circulation. 2004;94(suppl 1):442.

19. Dagum P, Timek TA, Green GR, Lai D, Daughters GT, Liang DH, et al. Coordinate-free analysis of mitral valve dynamics in normal and ischemic hearts. Circulation. 2000;102(suppl):III62-9.

20. Tibayan FA, Rodriguez F, Zasio MK, Bailey L, Liang D, Daughters GT, et al. Geometric distortions of the mitral valvular-ventricular complex in chronic ischemic mitral regurgitation. Circulation. 2003; 108(suppl 1):II116-21.

21. Gorman JH III, Gorman RC, Jackson BM, Enomoto Y, John-Sutton MG, Edmunds LH Jr. Annuloplasty ring selection for chronic ischemic mitral regurgitation: lessons from the ovine model. Ann Thorac Surg. 2003;76:1556-63.

22. Messas E, Guerrero JL, Handschumacher MD, Conrad CP, Chow C, Sullivan S, et al. Chordal cutting: a new therapeutic approach for ischemic mitral regurgitation. Circulation. 2001;104:1958-63.

23. Kron IL, Green GR, Cope JT. Surgical relocation of the posterior papillary muscle in chronic ischemic mitral regurgitation. Ann Thorac Surg. 2002;74:600-1.

24. Gorman JH III, Jackson BM, Enomoto Y, Gorman RC. The effect of regional ischemia on mitral valve annular saddle shape. Ann Thorac Surg. 2004;77:544-8.

25. Walmsley R. Anatomy of human mitral valve in adult cadaver and comparative anatomy of the valve. Br Heart J. 1978;40:351-66.

\section{Online-www.aats.org}

Now you can get The Journal of Thoracic and Cardiovascular Surgery online. The Journal online brings you faster delivery time, easy searching of current and back issues, links to PubMed, AATS, WTSA, and other important sites, and more. Visit the Journal online today.

\section{Receive tables of contents by e-mail}

To receive the tables of contents by e-mail, sign up through our Web site at http://www.mosby.com/jtcvs

Choose E-mail Notification

Simply type your e-mail address in the box and click the Subscribe button. Alternatively, you may send an e-mail message to majordomo@mosby.com. Leave the subject line blank and type the following as the body of your message: subscribe jtcvs_toc

You will receive an e-mail to confirm that you have been added to the mailing list.

Note that TOC e-mails will be sent out when a new issue is posted to the Web site. 